\title{
Introduction to the epidemiology of coercive measures in Spanish closed institutions
}

\author{
Francisco Torres-González*1, Pilar Nonay ${ }^{1}$, Claudio Hernandez ${ }^{1}$, \\ Luis Fernando Barrios ${ }^{2}$, Ángeles López ${ }^{3}$, José Hervás ${ }^{4}$, Fermín Mayoral ${ }^{5}$ and \\ Eloy Girela ${ }^{6}$
}

\begin{abstract}
Address: ${ }^{1}$ Department of Legal Medicine and Psychiatry, University of Granada, Granada, Spain, ${ }^{2}$ Department of Administrative Law, University of Alicante, Alicante, Spain, ${ }^{3}$ Psychiatric Penitentiary, Hospital of Foncalent, Alicante, Spain, ${ }^{4}$ Department of Internal Medicine, University of Granada, Granada, Spain, ${ }^{5}$ Carlos Haya University Hospital, University of Malaga, Malaga, Spain and ${ }^{6}$ Department of Legal Medicine, University of Cordoba, Cordoba, Spain

* Corresponding author
\end{abstract}

from WPA Thematic Conference. Coercive Treatment in Psychiatry: A Comprehensive Review

Dresden, Germany. 6-8 June 2007

Published: 19 December 2007

BMC Psychiatry 2007, 7(Suppl I):S44 doi:I0.I I86/I47I-244X-7-SI-S44

This abstract is available from: http://www.biomedcentral.com/I47I-244X/7/SI/S44

(c) 2007 Torres-González et al; licensee BioMed Central Ltd.

\section{Background}

During the execution of the European EUNOMIA study, the lack of specific norms on the issue was observed; further, it became evident that coercive measures were not only applied to the mentally ill, but to all sorts of people admitted to close institutions; i.e.: general hospitals, nursing homes, and penitentiary centers. Therefore, we developed several add-on EUNOMIA studies on different sorts of Spanish closed institutions, aiming to analyze the existing legal framework for each of these institutions and to observe the practice through epidemiological studies.

\section{Methods}

To choose suitable institutions where people could be admitted without consent and where users could suffer other coercive measures while staying there; to develop specific epidemiological designs and methods for each study according to the different institutional profiles, to analyze specific applicable legislation for the different settings, and to take advantage of the European study trying to use as much as possible similar criteria and its basic layout of variables and questionnaires, and doing only the necessary adaptation to each particular institution.

\section{Results}

Three studies are meanwhile carried out in primarily nonpsychiatric institutions, which are on different stage of execution: coercive measures in general hospitals on non mentally-ill patients, coercive measures on prison inmates with mental disorders, and coercive measures in homes for the mentally retarded. The two first projects are presented at this symposium.

\section{Conclusion}

This group of interconnected studies, following all of them similar background and methodology, will show evidence on two facts: First, coercion is not reserved for the mentally ill people. Second, there is a need to harmonize legal norms for users of the health, social and penitentiary system beyond the traditional concern with mentally ill people. 